\title{
Intimate partner violence in urban Pakistan: prevalence, frequency, and risk factors
}

This article was published in the following Dove Press journal:

International Journal of Women's Health

15 March 20II

Number of times this article has been viewed

\section{Tazeen S Ali ${ }^{1,2}$ \\ Nargis Asad ${ }^{3}$ \\ Ingrid Mogren ${ }^{4}$ \\ Gunilla Krantz ${ }^{5}$}

'School of Nursing, Aga Khan University, Karachi, Pakistan;

${ }^{2}$ Department of Public Health

Sciences, Division of Global Health,

Karolinska Institutet, Stockholm,

Sweden; ${ }^{3}$ Department of Psychiatry,

Aga Khan University, Karachi,

Pakistan; ${ }^{4}$ Department of Clinical

Science, Obstetrics and Gynecology,

Umeå University, Umeå, Sweden;

${ }^{5}$ Department of Public Health

and Community Medicine/Social

Medicine, The Sahlgrenska Academy

at University of Gothenburg,

Göteborg, Sweden
Correspondence: Tazeen Saeed Ali

School of Nursing, Aga Khan University,

Stadium Road, PO Box 3500,

Karachi 74800, Pakistan

Tel +92213493005 I

$\mathrm{Fax}+922134934294$

Email tazeen.ali@aku.edu
Background: Intimate partner violence (IPV) is an important public health issue with severe adverse consequences. Population-based data on IPV from Muslim societies are scarce, and Pakistan is no exception. This study was conducted among women residing in urban Karachi, to estimate the prevalence and frequency of different forms of IPV and their associations with sociodemographic factors.

Methods: This cross-sectional community-based study was conducted using a structured questionnaire developed by the World Health Organisation for research on violence. Community midwives conducted face-to-face interviews with 759 married women aged 25-60 years.

Results: Self-reported past-year and lifetime prevalence of physical violence was 56.3 and $57.6 \%$, respectively; the corresponding figures for sexual violence were $53.4 \%$ and $54.5 \%$, and for psychological abuse were $81.8 \%$ and $83.6 \%$. Violent incidents were mostly reported to have occurred on more than three occasions during the lifetime. Risk factors for physical violence related mainly to the husband, his low educational attainment, unskilled worker status, and five or more family members living in one household. For sexual violence, the risk factors were the respondent's low educational attainment, low socioeconomic status of the family, and five or more family members in one household. For psychological violence, the risk factors were the husband being an unskilled worker and low socioeconomic status of the family.

Conclusion: Repeated violence perpetrated by a husband towards his wife is an extremely common phenomenon in Karachi, Pakistan. Indifference to this type of violence against women stems from the attitude that IPV is a private matter, usually considered a justifiable response to misbehavior on the part of the wife. These findings point to serious violations of women's rights and require the immediate attention of health professionals and policymakers.

Keywords: intimate partner violence, domestic violence, Pakistan, gender inequality, prevalence, frequency, risk factors

\section{Introduction}

Intimate partner violence (IPV) is the most common form of violence faced by women in both high- and low-income countries and, due to its magnitude, is recognized as a substantial public health problem. ${ }^{1}$ One in three women worldwide is reported to experience IPV at some point in her life. ${ }^{2}$ This violence confers tremendous suffering on the women affected, as well as on their children. ${ }^{3,4}$ According to the World Health Organisation's multicountry study on violence against women in intimate relationships, the lifetime prevalence of physical or sexual violence ranges between $15 \%$ and $71 \%$, and past-year prevalence also shows a wide variation (4\%-54\%), with the lowest rates found for Japan and the highest for Ethiopia, Peru, and Bangladesh. ${ }^{4}$ 
There are different theoretical models that can be used to understand why violence occurs within intimate relationships. These include psychopathological, sociological, gender, and family systems theories. Sociological theories indicate that low education, economic vulnerability, stress, lack of support from authorities (healthcare services, social welfare), and a closed social network increase the risk of IPV. ${ }^{5}$ Gender theories describe the cultural and social constructions of gender, where masculinity is associated with aggression and power, and femininity with subordination. ${ }^{5,6}$ This, in combination with a material gender-power dimension, where men are assigned more economic and political power and where women are more dependent, increases the risk of violence. Psychopathological theories bring in individual men's interpersonal problems and functional deficits, including certain psychiatric diseases explaining variations between individuals. Family systems theories focus on communication, relationship, and problem-solving skills of couples in whom violence occurs. ${ }^{5}$

Pakistan is a low-income country with 172 million inhabitants. It is a male-dominated society, where partner violence is accepted as a cultural norm and viewed as normal behavior within a marriage. ${ }^{7}$ Indifference to this type of violence against women stems from attitudes that partner violence is a private matter and usually a justifiable response to misbehavior on the part of the wife, although it is understood as being against Islamic teachings. ${ }^{7-9}$ Most Pakistani women are ignorant of the fact that violence is a crime, and those who do report violence fear punitive action from the husband's family and/or losing their children, and few women of middle and lower class backgrounds can survive independently. ${ }^{10}$ Moreover, social norms strongly discourage women from living on their own, especially young women. ${ }^{10}$

Poverty is a substantial problem faced by a large proportion of the population, resulting in ongoing efforts to satisfy the basic necessities of life. ${ }^{11}$ According to the 2000-2007 Pakistan demographic health survey, more than half of the women and about one-third of the men in Pakistan lack basic education. ${ }^{12}$ Approximately $30 \%$ of women are in some kind of paid employment, ${ }^{12}$ but most women in Pakistan are confined to the home, doing housework for the extended family, and are excluded from decision-making. ${ }^{7}$

Studies from Pakistan on IPV against wives are few. Furthermore, these studies are either facility-based, based on small convenience samples, and/or conducted outside of urban Karachi. These studies indicate a prevalence of $16 \%-76 \%$ for physical violence and $12 \%-16 \%$ for sexual violence. For psychological violence, the prevalence was found to be at least $23 \%$ and reaching extremely high levels $(>60 \%),{ }^{7,13,14}$ with a rising trend noted during the past 30 years for all three forms of violence. ${ }^{10}$

Studies in other Asian countries have also reported high prevalence figures. In rural Vietnam, the lifetime and past-year experience of physical IPV amounted to $31 \%$ and $8 \%$, respectively. ${ }^{15}$ The Indian National Family Health Survey, conducted across all Indian states in 2005-2006, found that $35 \%$ of 28,139 married women reported experiencing life-time physical IPV, with or without sexual violence from their husbands, $7.9 \%$ reported both physical and sexual IPV, and $28 \%$ reported experiencing physical IPV only. ${ }^{16}$ From eastern India, a study of 1718 married women found that $16 \%$ were exposed to physical violence and $25 \%$ to sexual violence, while $52 \%$ suffered psychological abuse in their lifetime. ${ }^{17}$ Another study from India comprising 9938 women aged 15-49 years reported a high prevalence of physical violence (40\%). ${ }^{18}$ A study from Iran of 2400 married women found that $15 \%$ had suffered physical abuse from their husbands in the previous year, $42 \%$ sexual abuse, and $82 \%$ various degrees of psychological abuse. ${ }^{19}$

Cultural norms in Pakistan stipulate that violence against women is not to be discussed openly. ${ }^{7}$ To perform a large-scale community-based study on this topic demands collaboration with local health organizations, because government-run health facilities are often poorly staffed and without resources for research and surveillance studies.

The aim of this community-based study, conducted among married women living in low- and middle-income areas in urban Karachi, was to investigate the prevalence and frequency of physical and sexual violence and psychological abuse perpetrated by husbands against their wives, and any associated sociodemographic risk factors.

\section{Methods}

\section{Study design and population}

This cross-sectional study was performed in Karachi, Pakistan. Karachi has about 16 million inhabitants and forms a district within the Sindh province. ${ }^{12}$ Karachi is further divided into 18 towns. In this study, 759 married women aged 25-60 years, living in two of the towns with approximately 720,000 inhabitants, were included. The response rate was $93.7 \%$.

Due to the restrictive attitudes concerning women's movements and decision-making in Pakistani society, ${ }^{14,20}$ it was necessary to link up with a health organization that maintained a surveillance system for data collection and 
had health workers who were known in the community. Government health facilities were initially contacted, but because they lacked resources, we were advised to contact the Health and Nutrition Development Society (HANDS). ${ }^{21}$ HANDS is a nongovernmental organization working closely with the government health services, and provides basic health facilities, primary education, and income-generating opportunities, as well as institutions to empower communities in the low- and middle-income areas of Karachi. ${ }^{21}$ HANDS facilities are equipped with trained people who shoulder full responsibility for local healthcare services at the primary care level (maternal and child health, immunization, oral rehydration therapy, control of diarrheal diseases, nutrition counseling, growth monitoring, treatment of minor illnesses), and field sites have been established to follow up on these activities. Community midwives with 18 months of training are available at these facilities to provide general antenatal and postnatal care, to assist during deliveries, and to provide family planning services. ${ }^{21}$ These midwives carried out the data collection for this study.

HANDS manages the health facilities in two major towns (Gadap and Bin Qasim), and has established 10 health field sites in these towns. For this study, six of these health field sites were randomly chosen for data collection. Many different ethnic populations reside in these towns. Socioeconomically, the population belongs mainly to the lower and middle socioeconomic strata. ${ }^{22}$ Therefore, the data gathered from these two towns can only be generalized to the lower and middle socioeconomic groups of Karachi. ${ }^{22,23}$

\section{Data collection}

The data collection instrument used was the Multi-country Study on Women's Health and Life Experiences Questionnaire developed by the World Health Organisation for public health research, with a focus on interpersonal violence. ${ }^{24}$ The questionnaire was developed for use in different cultures and is considered to be crossculturally appropriate. To date, it has been used in more than 15 countries. The abuse questions were developed on the basis of a variety of other abuse assessment scales (Index of Spouse Abuse and the Conflict Tactics scales) with established reliability and construct validity. ${ }^{25,26}$

This instrument was translated into Urdu, the national language generally spoken in Pakistan. A few items were excluded, regarded as being unacceptable in this context, such as women's alcohol consumption patterns, whether women acted as heads of the households, and if the husband had multiple sex partners. The questionnaire went through face and content validity assessment by experts, including a psychologist, an epidemiologist, a sociologist, a community-based medical doctor, the field supervisor, a public health specialist, and the data collectors. The final questionnaire contained items addressing sociodemographic and psychosocial factors, general and reproductive health, different forms of violence, its frequency, and any health effects of the violence inflicted.

The data were collected by community midwives employed by HANDS in March-August 2008, using a multistage random sampling technique in the selected area (Figure 1). In each field site, and via the surveillance system set up by the community midwives, the required number of households was randomly selected (using computer-generated numbers from Epi Info ${ }^{\mathrm{TM}}$ ) from a list of all households in which women of the required age resided. Ten women refused to participate in the initial stage of the interview and were replaced by a neighboring woman of the same age. A further 41 women decided to discontinue the interview when half-way through, and were not replaced, which gave a dropout rate of $6.3 \%$. In a household with more than one eligible woman, only one woman was selected, by asking the youngest and the oldest, alternately. Information related to the husbands was obtained from the women, and relates only to the current husband.

\section{Sample size calculation}

In order to detect a 1.6-fold increase in risk of physical, sexual, and/or psychological violence and abuse with $80 \%$ probability and an estimated $20 \%-30 \%$ prevalence rate in the study sample, we calculated that we needed a sample size of about

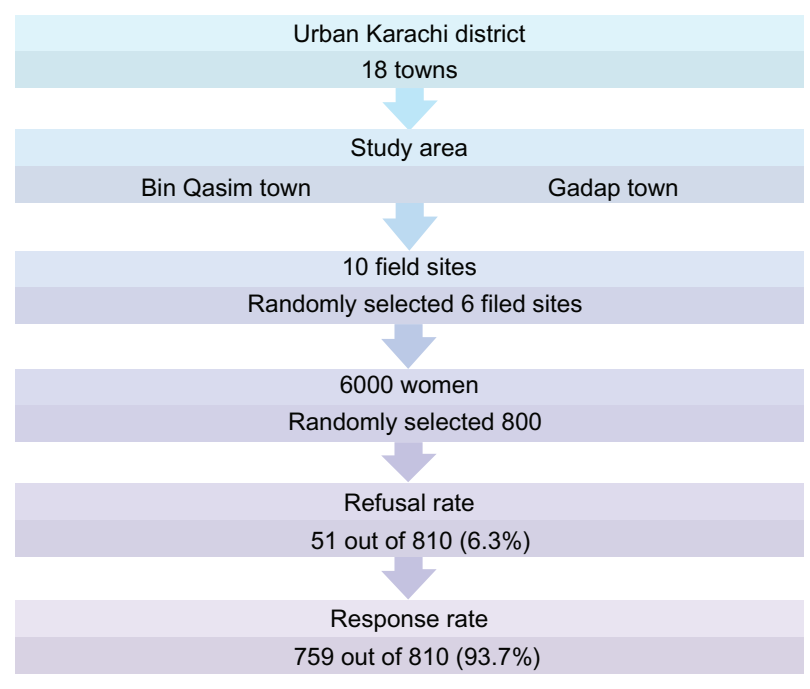

Figure I The sampling strategy of the study and its response rate. 
664 individuals. It was decided to aim for 800 respondents, and 810 were approached. In total, 759 women were included in the study.

\section{Training of data collectors}

Six community midwives received training for one week, conducted by the main author of this study and a psychologist in collaboration with members of the Women Lawyers' Association (a nongovernmental organization that supports women's legal rights) and HANDS. The training included the rationale behind the study, known prevalence and causes of IPV, women's vulnerability, ethical considerations, and communication and interview skills. Two of the interviewers were lost during the training period and four data collectors continued.

Each interview was conducted in the local language, Urdu. The study was presented as a women's health study to the household members, and not until the conversation was safe from being overheard were any sensitive questions asked. The interviews were conducted in the respondent's home, where privacy could be ensured, otherwise at a nearby school or HANDS facility. To ensure quality of the data, about $5 \%$ of the participants were reinterviewed at random, and only minor differences were detected in the responses given.

\section{Variables \\ Dependent variables}

IPV is defined as any act of physical, sexual, or psychological abuse by a current or former partner, whether cohabiting or not. ${ }^{4}$ Physical violence was measured as moderate (slapping, throwing things, pushing, shoving) or severe (hitting, kicking, dragging, beating, choking, burning). Sexual violence was defined as being coerced to perform sexual acts against the woman's will and physically forced into sexual intercourse by the husband. Psychological abuse was measured as insulting the woman or making her feel bad about herself, belittlement or humiliation in front of others, doing things to scare or intimidate her on purpose, and threats to hurt her or someone she cared about. Lifetime exposure to violence after marriage was assessed by items assessing acts of violence, forming composite measures for physical, sexual, and psychological violence, respectively, along with their frequency (how often it had occurred). Past-year exposure was obtained as a summary measure only of the different forms of violence and not by individual items. For bivariate and multivariate analyses, the dependent variables were dichotomized into experience of violence as opposed to no experience of physical or sexual violence or psychological abuse, respectively.

\section{Independent variables}

Sociodemographic variables were analyzed as independent risk factors. Age was divided into three groups and later dichotomized into younger and older age groups (25-35 years and 36-60 years). Educational attainment was grouped into no education, primary (up to eight years), secondary schooling (9-10 years), intermediate (11-12 years), and higher education (at least 13 years), and for multivariate purposes education was dichotomized into no formal education as opposed to any length of schooling. The employment status of the husbands and wives were dichotomized into being employed or not. Those that were in paid employment were further categorized as unskilled workers (eg, construction, messenger, landlord, farmer, watchman, servant, shopkeeper), skilled workers (eg, fisherman, gardener, carpenter, trader, driver, tailor), and low- and medium-level professionals (eg, soldier, police officer, teacher, health professionals, receptionist, secretary, lady health visitor, school teacher). This variable was further dichotomized into skilled workers (including the professionals), and unskilled workers.

The socioeconomic status variable was constructed from a list of household assets. Each respondent marked the assets available in the household and these assets were assigned different weights according to how common they were in households and their market price, eg, electricity, radio, and/or television (rated as 1), telephone and/or computer (2), and refrigerator and/or air conditioner (3). The weightings were determined by a team of researchers from the Aga Khan University, with experience of conducting communitybased studies. The weights were summed and divided into quartiles. Families up to the 25 th centile were rated as being of low socioeconomic status, and then each quartile was rated as lower-middle socioeconomic status, upper-middle socioeconomic status, and high socioeconomic status, respectively. Socioeconomic status was further dichotomized into low socioeconomic status as the exposure category versus middle and upper socioeconomic status. This way of grouping households into different socioeconomic status groups has also been used by other studies in this area. ${ }^{27,28}$

The number of children was grouped into five categories, ie, $0,1-2,3-4,5-6$, and $\geq 7$. This variable was thereafter dichotomized into $0-4$ children as opposed to $\geq 4$. The number of family members was measured as those living 
together and sharing one kitchen in a household. The variable was dichotomized into the number of members in the family. One to four members was considered the reference and $\geq 5$ as the exposure category.

\section{Statistical analysis}

SPSS (v 10.0; SPSS Inc, Chicago, IL) was used for all statistical calculations. ${ }^{29}$ Odds ratios (OR) with a 95\% confidence interval (CI) level were used in the bivariate and multivariate analyses to estimate associations between sociodemographic variables and lifetime exposure to all three forms of violence. Statistically significant variables in the bivariate analyses were entered into the multivariate model, one at a time. Final models are displayed.

\section{Ethical considerations}

The ethical principles of violence research defined by the World Health Organization were strictly followed. ${ }^{30}$ All respondents were informed about their free choice to participate and to withdraw whenever they wished during the research phase. Data collectors secured written consent from all respondents before the interview. Those women who disclosed experiences of violence and expressed a need for support were referred to the Pakistan Women Lawyers Association and Women's Social Security Department, Government of Pakistan, a social welfare department for women, located in the Sindh secretariat, where counseling is given by female lawyers and social workers, who further offer support in divorce cases and provide income generation schemes to victims of violence. The study was approved by the Institutional Ethical Review Committee of Aga Khan University in Karachi, Pakistan. Linking up with the HANDS organization secured the data collection process, because unfamiliar women introducing themselves as data collectors would hardly have been accepted by the families. Furthermore, data collectors unfamiliar to the households may have been put at personal risk. The women who participated in the study were provided with referrals to mental health professionals, and lawyers for a free of cost consultation. Moreover, women in the community were also given awareness sessions by the lawyers with regard to women's rights.

\section{Results}

\section{Sociodemographic pattern}

Of the participating women, about half had no formal education (47.6\%) and the majority of them were housewives (Table 1). Of the male spouses, $36.2 \%$ had no formal
Table I Sociodemographic and psychosocial factors of respondents and their husbands $(n=759)$

\begin{tabular}{|c|c|c|}
\hline Characteristics & $n=759$ & $\%$ \\
\hline \multicolumn{3}{|l|}{ Respondents } \\
\hline \multicolumn{3}{|l|}{ Age group (years) } \\
\hline $25-35$ & 447 & 58.9 \\
\hline $36-45$ & 228 & 30.0 \\
\hline $46-60$ & 84 & II.I \\
\hline \multicolumn{3}{|l|}{ Education } \\
\hline No formal education & 361 & 47.6 \\
\hline Primary school ( $<6$ years) & 175 & 23.1 \\
\hline Secondary school (6-8 years) & 110 & 14.5 \\
\hline Secondary school (9-10 years) & 87 & 11.5 \\
\hline Intermediate ( $11-12$ years $)$ & 17 & 2.2 \\
\hline Higher education ( $\geq 13$ years) & 9 & 1.2 \\
\hline \multicolumn{3}{|l|}{ Employed } \\
\hline Yes & 110 & 14.5 \\
\hline No & 649 & 85.5 \\
\hline \multicolumn{3}{|l|}{ Occupation } \\
\hline Housewife & 649 & 85.5 \\
\hline Unskilled workers & 18 & 2.4 \\
\hline Skilled workers & 51 & 6.7 \\
\hline Low and medium level professionals & 42 & 5.5 \\
\hline \multicolumn{3}{|l|}{ Husbands/partners } \\
\hline \multicolumn{3}{|l|}{ Age group (years) } \\
\hline $25-35$ & 307 & 40.4 \\
\hline $36-45$ & 263 & 34.7 \\
\hline $46-90$ & 189 & 24.9 \\
\hline \multicolumn{3}{|l|}{ Education } \\
\hline No formal education & 275 & 36.2 \\
\hline Primary school ( $<6$ years) & 89 & 11.7 \\
\hline Lower secondary school (6-8 years) & 108 & 14.2 \\
\hline Higher secondary school (9-10 years) & 185 & 24.4 \\
\hline Intermediate ( $11-12$ years $)$ & 63 & 8.3 \\
\hline Higher education ( $\geq 13$ years) & 39 & 5.1 \\
\hline \multicolumn{3}{|l|}{ Employed } \\
\hline Yes & 746 & 98.3 \\
\hline No & 13 & 1.7 \\
\hline \multicolumn{3}{|l|}{ Occupation } \\
\hline Unemployed & 13 & 1.7 \\
\hline Unskilled workers & 500 & 65.9 \\
\hline Skilled workers & 145 & 19.1 \\
\hline Low and medium level professionals & 101 & 13.3 \\
\hline \multicolumn{3}{|l|}{ Family factors } \\
\hline \multicolumn{3}{|l|}{ Socioeconomic status } \\
\hline Low & 242 & 31.9 \\
\hline Medium low & 172 & 22.7 \\
\hline Medium high & 202 & 26.6 \\
\hline High & 143 & 18.8 \\
\hline \multicolumn{3}{|l|}{ Number of children } \\
\hline 0 children & 41 & 5.4 \\
\hline I-2 children & 249 & 32.8 \\
\hline $3-4$ children & 221 & 29.1 \\
\hline 5-6 children & 170 & 22.4 \\
\hline$\geq 7$ children & 78 & 10.3 \\
\hline \multicolumn{3}{|l|}{ Number of family members } \\
\hline I-4 family members & 266 & 35.0 \\
\hline 5-17 family members & 493 & 65.0 \\
\hline
\end{tabular}


schooling and $65.9 \%$ were unskilled workers. Of the families, $32.7 \%$ had more than four children, and $65.0 \%$ of the households contained five or more members.

\section{Forms of violence}

Of the 759 women, $57.6 \%$ reported a lifetime experience of physical violence and, of these, $54.2 \%$ reported severe incidents of physical violence (Table 2) and 56.3\% reported past-year exposure to physical violence. For sexual violence, the corresponding figures for lifetime and past-year prevalence were $54.5 \%$ and $53.4 \%$. For psychological violence, the corresponding figures were $83.6 \%$ and $81.8 \%$, respectively. In the majority of cases, violence was experienced as repeated acts, ie, more than three times per year (see Table 2 for detailed prevalence figures).

The different forms of violence and their overlapping nature are shown in detail as a Venn diagram of lifetime exposure in Figure 2. The most commonly occurring single form was psychological violence (19.1\%). An overwhelmingly large group reported all three forms of violence, ie, $43.9 \%$ $(n=333)$ in their lifetime and $87.1 \%(n=661)$ reported any kind of violence exposure.

\section{Associations with sociodemographic and psychosocial factors}

Poor socioeconomic life circumstances constituted the main risk factor for all forms of lifetime violence (Table 3). Older women were more at risk of physical and sexual violence than their younger counterparts, with an OR of 1.65 and a $95 \%$ Confidence Interval [CI] of 1.23-2.23. Physical and sexual violence were associated with almost identical risk factors, ie, no formal education for either the woman or the husband, older age of the husband, more than five children in the family, and living in an extended family setup, as compared with having fewer children and living in a smaller family, respectively (Table 3). Statistically significant risk factors for psychological abuse were the husband having no formal education (OR 2.21, CI: 1.41-3.47) and being an unskilled worker or unemployed (OR 3.18, CI: 2.15-4.71) and, linked to this, low socioeconomic status of the family (OR 2.21, CI: 1.37-3.54). The educational level of the husband had a statistically significant association with all three forms of violence over the lifetime. Analyses of risk factors for past-year experience of any forms of violence were carried out, but are not shown in the tables because these were almost the same as for lifetime exposure.

Table 2 Lifetime prevalence and frequency of different forms of violence among married women $(n=759)$

\begin{tabular}{|c|c|c|c|c|}
\hline \multirow[t]{3}{*}{ Forms of violence } & \multicolumn{4}{|c|}{ Life time prevalence } \\
\hline & \multirow[t]{2}{*}{$\begin{array}{l}\text { Violence } \\
\text { experienced }\end{array}$} & \multicolumn{3}{|c|}{$\begin{array}{l}\text { Number of } \\
\text { events }\end{array}$} \\
\hline & & $1-2$ & $3-4$ & $\geq 5$ \\
\hline Physical violence $^{a}$ & $\mathrm{n}(\%)$ & $\mathrm{n}(\%)$ & $\mathrm{n}(\%)$ & n (\%) \\
\hline \multicolumn{5}{|l|}{ Moderate physical violence } \\
\hline Slapped/threw something & $227(29.9)$ & $3(0.4)$ & $155(20.4)$ & $69(9.1)$ \\
\hline Pushed/shoved & $384(50.6)$ & $9(1.2)$ & $302(39.8)$ & $73(9.7)$ \\
\hline Summary measure of moderate physical violence & $402(53.0)$ & $9(1.2)$ & $318(41.9)$ & $75(9.9)$ \\
\hline \multicolumn{5}{|l|}{ Severe physical violence } \\
\hline Hit with a fist that could hurt & $306(40.3)$ & $8(1.1)$ & $230(30.3)$ & $68(8.9)$ \\
\hline Kicked/dragged or beating & $330(43.5)$ & $3(0.4)$ & $260(34.3)$ & $67(8.8)$ \\
\hline Choked or burnt on purpose & $183(24.1)$ & $3(0.4)$ & $|3|(\mid 7.3)$ & $49(6.5)$ \\
\hline Summary measure of severe physical violence & $4 I I(54.2)$ & $9(1.2)$ & $329(43.3)$ & $73(9.6)$ \\
\hline Summary measure of physical violence & $437(57.6)$ & $10(1.3)$ & $35 I(46.2)$ & $76(10.0)$ \\
\hline \multicolumn{5}{|l|}{ Sexual violence ${ }^{a}$} \\
\hline Physically forced to have sexual intercourse & 257 (33.9) & $5(0.7)$ & I $88(24.8)$ & $64(8.5)$ \\
\hline Did have sexual intercourse when you did not want too & $4 \mid 4(54.5)$ & $10(1.3)$ & $330(43.5)$ & $74(9.8)$ \\
\hline Summary measure of sexual violence & $4 \mid 4(54.5)$ & $10(1.3)$ & $330(43.5)$ & $74(9.8)$ \\
\hline \multicolumn{5}{|l|}{ Psychological abuse $^{a}$} \\
\hline Insulted or made her feel bad about herself & $586(77.2)$ & $\mathrm{I}(0.1)$ & $383(50.5)$ & $202(26.7)$ \\
\hline Belittled or humiliated her in front of others & $567(74.7)$ & $5(0.7)$ & $422(55.6)$ & $140(18.5)$ \\
\hline Did things to scare or intimidate her on purpose & $562(74.0)$ & $6(0.8)$ & $415(54.7)$ & I4I (I8.6) \\
\hline Threaten to hurt her or someone she cared about & $578(76.2)$ & $6(0.8)$ & $431(56.8)$ & $|4|(\mid 8.6)$ \\
\hline Summary measure of psychological abuse & $634(83.6)$ & $8(1.1)$ & $480(63.2)$ & $146(19.3)$ \\
\hline Psychological abuse alone & $145(19.1)$ & $3(0.4)$ & $128(16.9)$ & $14(1.8)$ \\
\hline
\end{tabular}

Note: aParticipants reported more than one incident. 


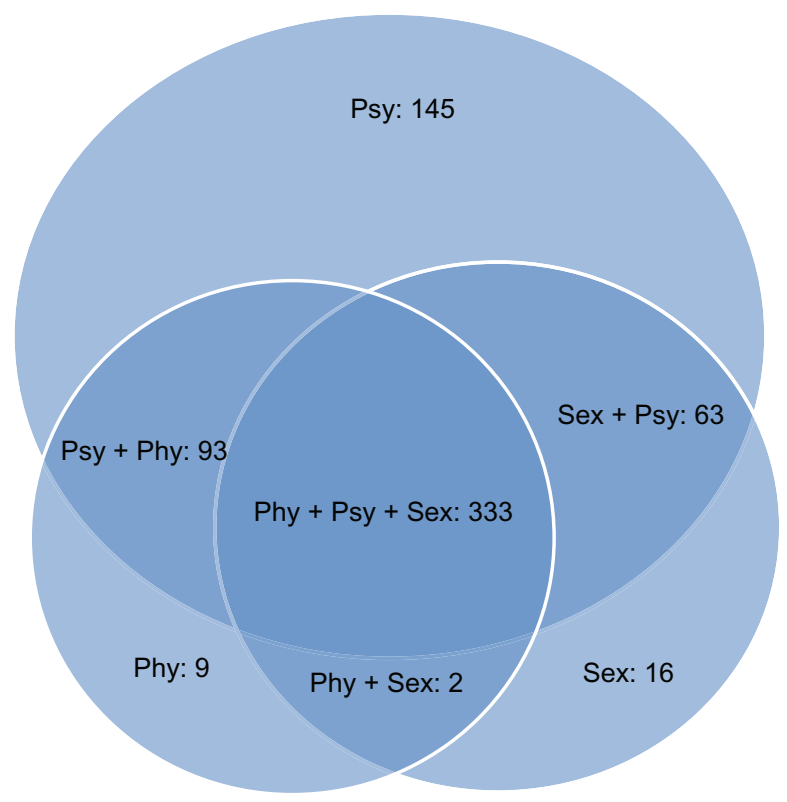

Figure 2 Venn diagram illustrating the overlapping between the different forms of violence for life time exposure. Physical (Phy), sexual (sex) and psychological (psy) violence. Number of women are given for each specified category.

Multivariate analyses were then performed to test for possible confounding factors (Table 4). For physical violence, factors related to the husband that were statistically significant included no formal education (adjusted OR 1.87, CI: 1.31-2.67), belonging to the unskilled worker group (adjusted OR 1.84, CI: 1.32-2.58), and number of family members being more than five in the household (adjusted OR 1.49, CI: 1.03-2.14). For sexual violence, the woman's lack of formal education (adjusted OR 2.27, CI: 1.65-3.12), more than five family members living in the household (adjusted OR 1.49, CI: 1.03-2.15), and low socioeconomic status (adjusted OR 1.89, CI: 1.35-2.65) proved to be statistically significant risk factors. For psychological abuse, the husband being an unskilled worker (adjusted OR 2.69, CI: 1.77-4.09) and of low socioeconomic status (adjusted OR 1.93, CI: 1.18-3.15) remained statistically significant in the multivariate analysis.

\section{Discussion}

The results of this study revealed extremely high lifetime and past-year prevalence rates, and also a high frequency of all forms of IPV against women belonging to the lower and middle income strata in Karachi. The picture that evolves is that psychological abuse seems to be present in more than $80 \%$ of the families. Furthermore, the prevalence figures for physical and sexual violence are of similar size; more than $50 \%$ of the population in this study reported such experiences, and $44 \%$ reported exposure to all three forms of violence. Our findings point to poor life circumstances contributing to IPV in this setting, including low occupational status of the husband, low family socioeconomic status, too many children, and living with extended family.

The major strength of our study was its community-based nature, and the respondents having been selected by random sampling. Furthermore, it comprised a comparatively large sample from a country where violence in the family is not discussed or questioned openly. In addition, a well-known instrument was used for data collection, and the response rate was extremely high (93.7\%). It was possible to reach out to individual women because data collection was done by community midwives who were well trusted in the community. This trust was essential because IPV is an extremely sensitive topic in Pakistan, where it is generally considered an inappropriate subject for a woman to discuss with a stranger.

One of the weaknesses in our study is that the two towns selected for this study comprised people only from the lower and middle socioeconomic strata, but failed to reach the upper socioeconomic strata. However, we do consider the data to be valid and representative of similar socioeconomic areas in Karachi, because the population was carefully selected at random in a multistaged procedure. There is reason to believe that violence against women is even more common in rural areas, squatter settlements, and the suburbs, due to extremely low educational attainment levels and poverty amongst both men and women.

A further weakness is that we were not able to acquire specific data on past-year violence exposure. The data collectors asked for detailed information on acts of violence and their frequency only for life-time experience. Past-year prevalence was inquired about as a summary ("has any of this happened in the past year?"), for physical, sexual, and psychological violence. Past-year prevalence data is often thought to be a more reliable assessment of IPV than events occurring over the lifetime because of less recall bias. ${ }^{12,15,31}$ However, pastyear prevalence figures were close in magnitude to lifetime figures in our study, which is interpreted as violence faced by women in Pakistani families being ongoing year by year, with few women being able to obtain a divorce as a way to end the violence. Support for this assumption also comes from recent focus group discussions with women living in the same area (unpublished data). It is also a fact that the women, due to continuous exposure to different forms of violence and abuse, may have difficulties in differentiating recent events exactly from more distant violence experiences. 
Table 3 Bivariate associations between sociodemographic factors and life time experience of physical, sexual, and psychological violence $(n=759)$

\begin{tabular}{|c|c|c|c|c|c|c|}
\hline \multirow[t]{2}{*}{ Variables } & \multicolumn{2}{|c|}{$\begin{array}{l}\text { Physical violence } \\
n=427\end{array}$} & \multicolumn{2}{|c|}{$\begin{array}{l}\text { Sexual violence } \\
n=402\end{array}$} & \multicolumn{2}{|c|}{$\begin{array}{l}\text { Psychological abuse } \\
n=621\end{array}$} \\
\hline & $\begin{array}{l}\text { n (\%) with } \\
\text { violence } \\
\text { experienced }\end{array}$ & OR $(95 \% \mathrm{Cl})$ & $\begin{array}{l}\text { n (\%) with } \\
\text { violence } \\
\text { experienced }\end{array}$ & OR $(95 \% \mathrm{Cl})$ & $\begin{array}{l}\text { n (\%) with } \\
\text { violence } \\
\text { experienced }\end{array}$ & OR $(95 \% \mathrm{Cl})$ \\
\hline \multicolumn{7}{|l|}{ Respondents' age (years) } \\
\hline $25-35$ & $235(52.6)$ & 1 & $229(5 \mathrm{I} .2)$ & I & $367(82.1)$ & 1 \\
\hline $36-60$ & $202(64.7)$ & $1.65(1.23-2.23)$ & $185(59.3)$ & $1.38(1.03-1.85)$ & $267(85.6)$ & $1.29(0.86-1.92)$ \\
\hline \multicolumn{7}{|l|}{ Respondents' education } \\
\hline Educated ( $1-15$ years $)$ & $205(5 I .5)$ & 1 & $172(43.2)$ & 1 & $332(83.4)$ & I \\
\hline No formal education & $232(64.3)$ & $1.69(1.27-2.27)$ & $242(67.0)$ & $2.67(1.99-3.59)$ & $302(83.7)$ & $1.02(0.69-1.49)$ \\
\hline \multicolumn{7}{|l|}{ Respondents' occupation } \\
\hline Skilled workers and professionals & $44(49.9)$ & I & $51(58.0)$ & 1 & $74(83.1)$ & I \\
\hline Unskilled workers & $15(75.0)$ & $0.74(0.47-1.14)$ & $14(66.7)$ & $1.20(0.77-1.88)$ & $19(950.0)$ & $1.02(0.57-1.84)$ \\
\hline Housewives & $378(58.2)$ & $1.87(0.66-5.31)$ & $349(53.7)$ & $1.73(0.64-4.65)$ & $54 \mid(83.2)$ & $3.43(0.45-26.01)$ \\
\hline \multicolumn{7}{|l|}{ Husband's age group (years) } \\
\hline $25-35$ & $153(49.8)$ & I & $150(48.9)$ & 1 & $249(8 I . I)$ & I \\
\hline $36-90$ & $284(62.8)$ & $1.70(1.26-2.28)$ & $264(58.4)$ & $1.47(1.09-1.96)$ & $385(85.2)$ & $1.33(0.90-1.97)$ \\
\hline \multicolumn{7}{|l|}{ Husband's education } \\
\hline Education ( $\mathrm{I}-\mathrm{I} 7$ years of schooling) & $240(49.6)$ & 1 & $239(49.4)$ & I & $387(80.0)$ & 1 \\
\hline No formal education & $197(7 \mid .6)$ & $2.57(1.87-3.53)$ & $175(63.6)$ & $1.79(1.32-2.43)$ & $247(89.8)$ & $2.2 \mathrm{I}(\mathrm{I} .4 \mathrm{I}-3.47)$ \\
\hline \multicolumn{7}{|l|}{ Husband's occupation } \\
\hline Skilled workers and professionals & II 3 (45.9) & I & $123(50.0)$ & 1 & $177(72.0)$ & I \\
\hline Unskilled workers and unemployed & $324(63.2)$ & $2.0 \mathrm{I}(\mathrm{I} .48-2.74)$ & $291(56.7)$ & 1.31 (0.96-I.78) & $457(89.1)$ & $3.18(2.15-4.71)$ \\
\hline \multicolumn{7}{|l|}{ Socioeconomic status } \\
\hline Medium and high & $290(56.1)$ & 1 & $256(49.5)$ & I & $416(80.5)$ & 1 \\
\hline Low & $147(60.7)$ & $1.21(0.89-1.65)$ & $158(65.3)$ & $1.92(1.40-2.63)$ & $218(90.1)$ & $2.21(1.37-3.54)$ \\
\hline \multicolumn{7}{|l|}{ Number of children } \\
\hline $0-4$ children & $27 \mid(53.0)$ & 1 & $265(51.9)$ & 1 & $419(82.0)$ & 1 \\
\hline$\geq 5$ children & $166(66.9)$ & $1.79(1.31-2.46)$ & $149(60.1)$ & 1.39.(1.03-1.90) & $215(86.7)$ & $1.43(0.93-2.20)$ \\
\hline \multicolumn{7}{|l|}{ Number of family members } \\
\hline $\mathrm{I}-4$ & $129(48.5)$ & 1 & $126(47.7)$ & I & $214(80.5)$ & 1 \\
\hline $5-17$ & $308(62.5)$ & $1.77(1.31-2.40)$ & $288(58.4)$ & $1.56(1.16-2.11)$ & $420(85.2)$ & $1.40(0.96-2.10)$ \\
\hline
\end{tabular}

Abbreviations: $\mathrm{OR}$, odds ratio; $\mathrm{Cl}$, confidence intervals.

The fact that community midwives performed the data collection does, however, increase the likelihood of accurate estimates because trust and confidence was established. Another limitation of a cross-sectional study is that it is not possible to establish causal relationships.

The high prevalence figures found for past-year and lifetime exposure of all three forms of violence can be understood in the light of the fact that women's opportunities to end the violence are few. This is due to perpetration of violence being considered as normal male behavior. The subordinate role of women in the society and family allows the violence to continue and keeps divorce rates low, especially among the low- and middle-income groups. ${ }^{9}$

The prevalence of violence in our study was higher than that found in studies conducted in Vietnam, India, and Bangladesh, ${ }^{15,16,32}$ but similar to findings from Iran, specifically for sexual and psychological violence. ${ }^{19}$ This might be due to the higher level of gender inequality among low- and middle-income women in Pakistan, who generally accept violence within marriage and poor life circumstances, but also due to a high level of trust in community midwives that made disclosures possible.

The multivariate analyses confirmed that low education and low occupational status of the husband were important risk factors for physical violence and perpetration of psychological abuse, but lack of formal education in women was only an important risk factor for sexual violence. In one of the earlier studies from Vietnam, we also noted that male factors (low educational attainment, poverty) were risk factors for partner violence against women. ${ }^{15}$ This is in line with what has also been found in other sociological and public health studies. ${ }^{4,16,33}$ Striving for job security can create conflict and stress among men of low educational achievement. Rather than using any other 
Table 4 Associations between sociodemographic and psychosocial variables with lifetime physical, sexual, and psychological violence, final models, presented as adjusted odds ratios with $95 \%$ confidence intervals $(n=759$ married women)

\begin{tabular}{|c|c|c|c|}
\hline & Physical & Sexual & Psychological \\
\hline \multicolumn{4}{|l|}{ Respondents' age (years) } \\
\hline $25-35 / 36-60$ & I.0I $(0.66-1.55)$ & $1.04(0.68-1.60)$ & $0.74(0.48-1.13)$ \\
\hline \multicolumn{4}{|l|}{ Respondents' education } \\
\hline Education/no formal education & $1.29(0.93-1.78)$ & $2.27(1.65-3.12)$ & - \\
\hline \multicolumn{4}{|l|}{ Husband's age (years) } \\
\hline $25-35$ & I & I & \\
\hline $36-90$ & $0.80(0.53-1.23)$ & $0.82(0.54-1.26)$ & - \\
\hline \multicolumn{4}{|l|}{ Husband's education } \\
\hline Education & 1 & I & I \\
\hline No formal education & $1.87(1.31-2.67)$ & $1.28(0.92-1.79)$ & $1.4 \mathrm{I}(0.86-2.3 \mathrm{I})$ \\
\hline \multicolumn{4}{|l|}{ Husband's occupation } \\
\hline Skilled workers and professionals & I & & I \\
\hline Unskilled workers and unemployed & $1.84(1.32-2.58)$ & - & $2.69(1.77-4.09)$ \\
\hline \multicolumn{4}{|l|}{ Number of children } \\
\hline 0-4 children & I & I & \\
\hline$\geq 5$ children & $1.26(0.84-1.88)$ & $0.92(0.62-1.37)$ & - \\
\hline \multicolumn{4}{|l|}{ No of family members } \\
\hline $\mathrm{I}-4$ & I & I & \\
\hline $5-17$ & $1.49(1.03-2.14)$ & $1.49(1.03-2.15)$ & - \\
\hline \multicolumn{4}{|l|}{ Socioeconomic status } \\
\hline Medium and high & & 1 & I \\
\hline Low socioeconomic & - & $1.89(1.35-2.65)$ & $1.93(1.18-3.15)$ \\
\hline
\end{tabular}

coping strategy, violence towards the wife may be used as a stress reliever. ${ }^{34}$

Low level of education in women as a risk factor for IPV exposure has been explained as being linked to a higher degree of acceptance of traditional gender roles than would be the case with better educated women, and thereby less ability to withstand such violence. ${ }^{35}$ The Iranian study similarly identified that illiterate and unemployed women were at a higher risk of violence. ${ }^{19}$ These findings emphasize the importance of education for both men and women. However, some studies from other countries ${ }^{32,34,36,37}$ have shown that better educated women sometimes face an increased risk of experiencing IPV, but this may be of a temporary nature.

Large family size was also identified as a risk factor for IPV. This can be explained by the fact that when the number of people in a household increases, financial stresses and miscommunication also increase, and this may result in violence towards the wife. ${ }^{32,38}$ Another study from Karachi also supports this finding, in that the presence of in-laws was found to be a risk factor for violent perpetration, and not only by the husband. ${ }^{13}$

The woman's age was not identified as a statistically significant risk factor for any of the forms of violence when controlled for in the multivariate analyses. However, there were indications in the bivariate analysis that older age could be a risk factor for physical and sexual violence. This can be interpreted as being due to the fact that violence against women in Pakistan is ongoing year-by-year, and older women will be more exposed over their lifetime.

Socioeconomic status was, in this study, a statistically significant factor for sexual violence and psychological abuse, which is in line with findings from other studies. ${ }^{15,39}$ This finding illustrates that within those families that are most vulnerable in terms of low education and low socioeconomic status, violence occurs more commonly. As has already been explained, this may be due to high stress levels, mirroring difficulties in managing everyday life, particularly in men, who are viewed as the main breadwinners. ${ }^{40}$

\section{Conclusion}

The prevalence of all forms of IPV being perpetrated in the lifetime was extremely high in the low- and middleincome strata in Karachi. Married women face this violence repeatedly. Sociodemographic factors were identified as contributing to the occurrence of this type of violence, with those having the least resources being most affected. The institutionalized and serious gender inequality accepted as a normal part of daily life by both women and men has contributed to the present situation. Few women are able to act on this by getting a divorce because a single woman's chances of living a decent life and taking care of her children alone are extremely limited. 
This situation requires serious and urgent attention at all levels of societal organization, by policymakers, political stakeholders, and professionals. Policy initiatives are needed, as are legal actions, to criminalize men's violence against women. Basic education needs to be made available for both girls and boys, with special attention placed on female education. Gender equality teaching and training should be included at different levels in the school curriculum. Healthcare staff and social authorities need training on the identification, counseling, management, and prevention of violence against women. Training of nurses and medical doctors in counseling of young couples for the prevention and management of IPV should be part of their basic education. Mass media involvement is necessary to create a debate on such gender discrimination practices and to encourage women's empowerment in society and in the family.

\section{Acknowledgments}

This study was made possible by a grant from the Swedish Foundation for International Cooperation in Research and Higher Education, and support from the Swedish Institute and the School of Nursing and The Community Health Department at the Aga Khan University, Karachi, Pakistan. The Department of Public Health and Community Medicine at Gothenburg University and the Department of Public Health Sciences, Division of Global Health, Karolinska Institutet, Stockholm, Sweden, also provided support during the manuscript analysis and preparation. We want to thank HANDS for supporting and facilitating the data collection and allowing the use of their surveillance system. We also want to acknowledge the Pakistan Women Lawyers' Association and the Women's Social Welfare Department for their strong support in the training of the data collectors. Last but not least, we want to thank the women who participated for their trust and confidence in this study.

\section{Disclosure}

The authors declare that they have no competing interests in this work.

\section{References}

1. Campbell JC, Abrahams N, Martin L. Perpetration of violence against intimate partners: Health care implications from global data. CMAJ. 2008;179(6):511-512.

2. Velzeboer M, Ellsberg M, Arcas C, Garcia-Moreno C. Violence Against Women: The Health Sector Responds. Washington, DC: Pan American Health Organization; 2003.

3. Garcia-Moreno C, Heise L, Jansen H, Ellsberg M, Watts C. Public healthviolence against women. Science. 2005;310(5752):1282-1283.
4. Garcia-Moreno C, Jansen H, Ellsberg M, Heise L, Watts CH; WHO Multi-country Study on Women's Health and Domestic Violence against Women Study Team. Prevalence of intimate partner violence: Findings from the WHO multi-country study on women's health and domestic violence. Lancet. 2006;368(9543):1260-1269.

5. Cunningham A, Jaffe PG, Baker L, et al. Theory-derived explanations of male violence against female partners: Literature update and related implications for treatment and evaluation. London, UK: London Family Court Clinic; 1998.

6. Courtenay WH. Constructions of masculinity and their influence on men's well-being: A theory of gender and health. Soc Sci Med. 2000; 50(10): 1385-1401.

7. Rabbani F, Qureshi F, Rizvi N. Perspectives on domestic violence: Case study from Karachi, Pakistan. East Mediterr Health J. 2008; 14(2):415-426.

8. Douki S, Nacef F, Ben Zineb S. Women's mental health in the Arab and Islamic world. J Psychosom Res. 2003;55(2):119.

9. Niaz U. Women's mental health in Pakistan. World Psychiatry. 2004; $3(1): 60-62$.

10. Khan A, Hussain R. Violence against women in Pakistan: Perceptions and experiences of domestic violence. Asian Stud Rev. 2008;32(2): 239-253.

11. Zingel WP. Alleviating urban poverty - the Pakistan way. In: Amitabh Kundu, editor. Manpower Journal. Special Issue on Impact of Structural Reforms on Employment Scenario. New Delhi, India: Institute of Applied Manpower Research; 1998. Available at: http://www.fao.org/fileadmin/ templates/FCIT/PDF/sofa.pdf. Accessed February 10, 2011.

12. Calverton M. Pakistan Demographic Health Survey 2006-7. Calverton, MD: Macro International Inc; 2007. Available at: http://www. measuredhs.com/pubs/pdf/FR200/FR200.pdf. Accessed February 10, 2011.

13. Fikree FF, Bhatti LI. Domestic violence and health of Pakistani women. Int J Gynaecol Obstet. 1999;65(2):195-201.

14. Karmaliani R, Irfan F, Bann C, et al. Domestic violence prior to and during pregnancy among Pakistani women. Acta Obstet Gynecol Scand. 2008;87(11):1194-1201.

15. Vung ND, Ostergren PO, Krantz G. Intimate partner violence against women in rural Vietnam - different socio-demographic factors are associated with different forms of violence: Need for new intervention guidelines? BMC Public Health. 2008;8:55.

16. Silverman JG, Decker MR, Saggurti N, Balaiah D, Raj A. Intimate partner violence and HIV infection among married Indian women. JAMA. 2008;300(6):703-710.

17. Babu BV, Kar KS. Domestic violence against women in eastern India: A population-based study on prevalence and related issues. BMC Public Health. 2009;9:9.

18. Kumar S, Jeyaseelan L, Suresh S, Ahuja RC. Domestic violence and its mental health correlates in Indian women. Br J Psychiatry. 2005; 187:62-67.

19. Faramarzi MES, Mosavi S. Prevalence and determinants of intimate partner violence in Babol City, Islamic Republic of Iran. East Mediterr Health J. 2005;11(5-6):870-879.

20. Andersson N, Cockcroft A, Ansari N, et al. Collecting reliable information about violence against women safely in household interviews: Experience from a large-scale national survey in South Asia. Violence Against Women. 2009;15(4):482-496.

21. Health And Nutrition Development Society. 2010; About HANDS. Available at: http://www.hands.org.pk/abouthands/abouthands.htm. Accessed June 5, 2010.

22. City District Government Karachi. Kolachi to Karachi. Available at: http://www.karachicity.gov.pk/. Accessed July 7, 2010.

23. Rozi S, Akhtar S, Ali S, Khan J. Prevalence and factors associated with current smoking among high school adolescents in Karachi, Pakistan. Southeast Asian J Trop Med Public Health. 2005;36(2):498-504.

24. World Health Organisation. Multicountry Study on Women's Health And Life Experiences Questionnaire (Version 9). Geneva, Switzerland: World Health Organisation; 2000. 
25. Hudson WW, McIntosh SR. The assessment of spouse abuse 2 Quantifiable dimensions. J Marriage Fam. 1981;43(4):873.

26. Straus MA, Hamby SL. The revised conflict tactics scales. Development and preliminary psychometric data. J Fam Issues. 1996;17(3): 283-316.

27. Hasnain F, Johansson E, Krantz G. What do young adults know about the HIV/AIDS epidemic? Findings from a population based study in Karachi, Pakistan. BMC Infect Dis. 2009;9:38.

28. Winkvist A, Akhtar HZ. God should give daughters to rich families only: Attitudes towards childbearing among low-income women in Punjab, Pakistan. Soc Sci Med. 2000;51(1):73-81.

29. Kinnear PGC. SPSS for Windows made simple. Release 10. Aberdeen, UK: University of Aberdeen; 2001.

30. World Health Organisation. Putting Women First. Ethical and Safety Recommendations for Research on Domestic Violence Against Women. Geneva, Switzerland: World Health Organisation; 2001.

31. Gil-Gonzalez D, Vives-Cases C, Ruiz MT, Carrasco-Portino M, Alvarez-Dardet C. Childhood experiences of violence in perpetrators as a risk factor of intimate partner violence: A systematic review. J Pub Health. 2008;30(1):14-22.

32. Bates LM, Schuler SR, Islam F, Islam K. Socioeconomic factors and processes associated with domestic violence in rural Bangladesh. Int Fam Plan Perspect. 2004;30(4):190-199.

33. Naved RT, Azim S, Bhuiya A, Persson LA. Physical violence by husbands: Magnitude, disclosure and help-seeking behavior of women in Bangladesh. Soc Sci Med. 2006;62(12):2917-2929.
34. Cano A, Vivian D. Life stressors and husband-to-wife violence. Aggress Violent Behav. 2001;6(5):459-480.

35. Ali TS, Gavino MI. Prevalence of and reasons for domestic violence among women from low socioeconomic communities of Karachi. East Mediterr Health J. 2007;13(6):1417-1426.

36. Castro R, Casique I, Brindis CD. Empowerment and physical violence throughout women's reproductive life in Mexico. Violence against Women. 2008;14(6):655-677.

37. Haj-Yahia MM. The incidence of witnessing interparental violence and some of its psychological consequences among Arab adolescents. Child Abuse Negl. 2001;25(7):885-907.

38. Farmer A, Thiefenthaler J. Domestic violence: The value of services as signals. Am Econ Rev. 1996;86(2):274-279.

39. Krieger N, Kaddour A, Koenen K, et al. Occupational, social, and relationship hazards and psychological distress among low income workers: Implications of the 'inverse hazard law'. J Epidemiol Community Health. 2011;65(3):260-272.

40. Stockdale SE, Wells KB, Tang L, Belin TR, Zhang L, Sherbourne CD. The importance of social context: Neighborhood stressors, stress-buffering mechanisms, and alcohol, drug, and mental health disorders. Soc Sci Med. 2005;65(9):1867-1881.
International Journal of Women's Health

\section{Publish your work in this journal}

The International Journal of Women's Health is an international, peerreviewed open-access journal publishing original research, reports, reviews and commentaries on all aspects of women's healthcare including gynecology, obstetrics, and breast cancer. Subject areas include Chronic conditions (migraine headaches, arthritis, osteoporosis);

\section{Dovepress}

Endocrine and autoimmune syndromes; Sexual and reproductive health; Psychological and psychosocial conditions. The manuscript management system is completely online and includes a very quick and fair peer-review system. Visit http://www.dovepress.com/ testimonials.php to read real quotes from published authors. 